\title{
LIML Estimation of Import Demand and Export Supply Elasticities
}

\author{
Vahagn Galstyan
}

TEP Working Paper No. 0316

March 2016

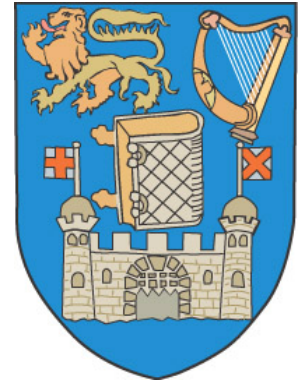

Trinity Economics Papers

\section{Department of Economics}

Trinity College Dublin 


\title{
LIML Estimation of Import Demand and Export Supply Elasticities
}

\author{
Vahagn Galstyan \\ Trinity College Dublin
}

June, 2016

\begin{abstract}
Following the seminal contribution of Feenstra (1994), I apply limited-information maximum likelihood to estimate import demand and export supply elasticities for a range of eurozone countries. The results highlight substantial inconsistencies in the parameters estimated by the methodology of Fuller (1977) relative to the parameters estimated by the methodology of Hausman et al (2012). The nature of the structural equations reveals complications generated by the limiting behavior of the parameters that can be replicated in finite samples. The results of simulations underscore substantial improvements in parameter estimates in a three-dimensional panel, suggesting that the problem of limiting behaviour can be overcome in larger dataset/panels.
\end{abstract}

JEL classification: F14, C13

Keywords: LIML, elasticity 


\section{Introduction}

Demand and supply elasticities play central roles in all economic applications. Accordingly, correct estimation of those elasticities bears non-negligible implications for both theoretical research and applied policy work. The goal of this paper is estimation of import demand and export supply elasticities.

One of the most important articles in this area is the seminal work of Feenstra (1994). Under a set of assumptions, the author derives a micro-founded equation with a set of parameters that can be used to extract the elasticities of import demand and export supply. To address endogeneity, Feenstra (1994) proposes estimating this equation by a two-stage least squares regression, where the instruments are exporter dummies. This approach of estimation has been adopted and further extended by Broda and Weinstein (2006). More recently, Soderbery $(2010,2015)$ proposes estimating the elasticities by applying the limited information maximum likelihood method of Fuller (1977) instead of two-stage least squares. While country-specific variance of residuals is necessary for identification, it can be a cause of substantial inconsistencies (Hausman e al 2012).

In this paper I use the methodologies developed by Fuller (1977) and Hausman et al (2012) to estimate import demand and export supply elasticities for a range of eurozone countries. My findings highlight presence of substantial inconsistency caused by heteroscedasticity. In relation to the estimated parameters, the cross-sectional average of the median elasticity of substitution stands at 1.81, while the cross-sectional average of the interquartile range is 1.33 . Turning to inverse export supply elasticities, the crosssectional average is 0.58 , while the corresponding average of the interquartile range is 1.41 .

In the vast majority of cases the estimated parameters by both estimation methodologies violate the theoretical restrictions of Feenstra (1994). Accordingly I study the limiting behavior of the structural equations when the structural parameters approach their theoretical limits. ${ }^{1}$ Monte-Carlo simulations reconfirm potential complications caused by the

\footnotetext{
${ }^{1}$ While these limits are unlikely to occur in data, one can be expect similar outcomes in finite samples when structural parameters are either relatively large or small.
} 
limiting behavior of the parameters: for a given elasticity of substitution $\sigma$, high inverse supply elasticity $\varpi$ raises both the median bias, the percentile range and the number of violated theoretical restrictions on parameters. Similar results hold for given $\varpi$ and high $\sigma$ pairs. The issue is addressed by re-estimating the parameters in a three-dimensional panel where I find that the expanded panel substantially improves both the median bias, the 9 th percentile range and the number of theoretical restrictions. ${ }^{2}$

The remainder of the paper is organized as follows. Section 2 describes the adopted empirical framework. Section 3 presents the data and shows that the estimates achieved by Hausman et al (2012) are consistent while those by Fuller (1977) are not. Furthermore, in the vast majority of cases the estimated parameters violate the theoretical restrictions. These cases are considered in Section 4, where I discuss the limiting behavior of the structural equations and present some baseline simulations. Finally, in section $5 \mathrm{I}$ present extended simulations with further pooled data that help mitigate the problem of imprecisions. Lastly, section 6 concludes.

\section{Theory and Estimations}

\subsection{Theoretical Framework}

The set-up of the problem is taken from Feenstra (1994). Let preferences for an import good take a CES form, $C_{t}=\left(\sum \varepsilon_{i, t}^{1 / \sigma} c_{i, t}^{1-1 / \sigma}\right)^{\sigma /(\sigma-1)}$. Consumption volume and a random preference parameter for variety $i$ at time $t$ are denoted by $c_{i, t}$ and $\varepsilon_{i, t}$ respectively. The substitution elasticity $\sigma$ is always greater than one. Under these assumptions, static optimization implies that the expenditure share of variety $i$ is a negative function of the corresponding relative price, $s_{i, t}=\varepsilon_{i, t}\left(p_{i, t} / P_{t}\right)^{1-\sigma}$. In the first log-difference, the demand function is

$$
\Delta \ln s_{i, t}=\phi_{t}-(\sigma-1) \Delta \ln p_{i, t}+\Delta \ln \varepsilon_{i, t}
$$

\footnotetext{
${ }^{2}$ Feenstra (1994), Broda and Weinsten (2006) and Soderbery $(2010,2015)$ rely on two-dimensional panel for a given importer: time and exporters. Pooling all importers adds an extra dimension to the panel and gives access to more data.
} 
where $\phi_{t}=(\sigma-1) \Delta \ln P_{t}$ is common across all varieties. To close the system assume that the supply curve is given by

$$
\Delta \ln p_{i, t}=\varpi \Delta \ln x_{i, t}+\Delta \ln u_{i, t}
$$

where $x_{j, t}$ is the volume of imports, $u_{i, t}$ captures random supply disturbances and $\varpi$ is the inverse supply elasticity. Furthermore, to allow for measurement error, assume that the logarithmic change in unit values is linearly related to the logarithmic change of unobservable price level

$$
\Delta \ln v_{i, t}=\Delta \ln p_{i, t}+\Delta \ln e_{i, t}
$$

Feenstra (1994) shows that equations (1) and (2), combined with their counterpart equations for a reference variety $k$, resulting in

$$
\left[\Delta \ln \tilde{v}_{i, t}\right]^{2}=\frac{\rho}{(\sigma-1)^{2}(1-\rho)}\left[\Delta \ln \tilde{s}_{i, t}\right]^{2}+\frac{2 \rho-1}{(\sigma-1)(1-\rho)}\left[\Delta \ln \tilde{s}_{i, t} \Delta \ln \tilde{v}_{i, t}\right]+v_{i, t}
$$

where tilde denotes deviation from the reference variety, while $\rho=\varpi(\sigma-1) /(1+\sigma \varpi)$. This last definition, in turn, implies that the following inequality must be true for the estimated parameters

$$
0 \leq \rho<(\sigma-1) / \sigma<1
$$

Finally, the error term $v_{i, t}$ is composed of cross-products between measurement errors, supply shocks and demand shocks. Assuming that all random disturbances are independent, the mathematical expectation of the error term $v_{i, t}$ converges to a constant. Correspondingly, I redefine the variables and coefficients and explicitly add a constant into the equation above as follows

$$
y_{i, t}=\eta_{0}+\eta_{1} x_{i, t}^{1}+\eta_{2} x_{i, t}^{2}+\varsigma_{i, t}
$$

Since the error terms are correlated with the regressors, the parameter vector is con- 
sistently estimated by an instrumental-variables regression, where the instruments are dummy variables across varieties (Feenstra 1994).

Once the parameter vector is consistently estimated, the import demand elasticity is obtained as

$$
\hat{\sigma}=1+\left(\frac{2 \hat{\rho}-1}{1-\hat{\rho}}\right) \frac{1}{\hat{\eta}_{2}}>1
$$

where

$$
\hat{\rho}=\left\{\begin{array}{l}
\frac{1}{2}+\left(\frac{1}{4}-\frac{1}{4+\hat{\eta}_{2}^{2} / \hat{\eta}_{1}}\right)^{1 / 2}: \hat{\eta}_{2}>0 \text { and } \hat{\eta}_{1}>0 \\
\frac{1}{2}-\left(\frac{1}{4}-\frac{1}{4+\hat{\eta}_{2}^{2} / \hat{\eta}_{1}}\right)^{1 / 2}: \hat{\eta}_{2}<0 \text { and } \hat{\eta}_{1}>0
\end{array}\right.
$$

When $\hat{\eta}_{1}<0$, equations (7) and (8) fail to provide estimates for $\hat{\sigma}$ and $\hat{\rho}$ such that $\hat{\sigma}>1$ and $0 \leq \hat{\rho}<1$. However, as long as $\rho \nless(\sigma-1) / \sigma$, it is possible to derive negative estimates of the inverse supply elasticity even when $\hat{\eta}_{1}>0$, and $\hat{\sigma}>1$ and $0 \leq \hat{\rho}<1$. $^{3}$ In this case Broda and Weinstein (2006) suggest a grid search procedure over a specified parameter space. This grid search procedure has been further extended by Soderbery (2015).

\subsection{Empirical Methodology}

Feenstra (1994) proposes estimating equation (6) by a two-stage least squares regression. Through Monte Carlo experiments, Soderbery (2010) shows that these estimates possesses substantial bias due to the problem of weak instruments. To correct for the bias, he proposes estimating the elasticities by the limited information maximum likelihood of Fuller (1977), with the estimated parameter vector given by

$$
\hat{\boldsymbol{\eta}}=\left(\mathbf{X}^{\prime} \mathbf{P} \mathbf{X}-\kappa \mathbf{X}^{\prime} \mathbf{X}\right)^{-1}\left(\mathbf{X}^{\prime} \mathbf{P} \mathbf{y}-\kappa \mathbf{X}^{\prime} \mathbf{y}\right)
$$

where $\mathbf{X}=\left[\mathbf{i}, \mathbf{x}^{1}, \mathbf{x}^{2}\right], \mathbf{P}=\mathbf{Z}\left(\mathbf{Z}^{\prime} \mathbf{Z}\right)^{-1} \mathbf{Z}^{\prime}, \mathbf{i}$ is a column vector of ones and $\mathbf{Z}$ is a matrix of predetermined variables and instruments, $\kappa=\left(\lambda-\frac{1-\lambda}{n}\right) /\left(1-\frac{1-\lambda}{n}\right)$ where $\lambda$ is the minimum eigenvalue of $\mathbf{A}=\left(\overline{\mathbf{X}}^{\prime} \overline{\mathbf{X}}\right)^{-1}\left(\overline{\mathbf{X}}^{\prime} \mathbf{P} \overline{\mathbf{X}}\right)$ and $\overline{\mathbf{X}}=[\mathbf{y}, \mathbf{X}]$. The results of simulations

\footnotetext{
${ }^{3}$ In fact, my estimations indicate that in substantial number of cases this inequality fails, generating positive elasticity of substitution and negative inverse supply elasticity.
} 
show substantial improvement in the precision of estimates. ${ }^{4}$

It is well known that under homoscedasticity the limited-information maximum likelihood of Fuller (1977) reduces the bias substantially (Davidson and MacKinnon 1993). In case of heteroscedastic residuals, however, the estimator is consistent only under a certain set of conditions. Hausman et al (2012) show that heteroscedasticity does not affect consistency of estimated parameters when the projection of endogenous regressors on the residual is not group specific and/or dummy instruments are of equal group sizes. When these conditions are violated, to generate consistent parameter estimates Hausman et al (2012) modify equation (9) as follows

$$
\hat{\boldsymbol{\eta}}=\left(\mathbf{X}^{\prime} \mathbf{P} \mathbf{X}-\sum_{i} \mathbf{P}_{i i} \mathbf{X}_{i}^{\prime} \mathbf{X}_{i}-\kappa \mathbf{X}^{\prime} \mathbf{X}\right)^{-1}\left(\mathbf{X}^{\prime} \mathbf{P} \mathbf{y}-\sum_{i} \mathbf{P}_{i i} \mathbf{X}_{i}^{\prime} \mathbf{y}_{i}-\kappa \mathbf{X}^{\prime} \mathbf{y}\right)
$$

where $\mathbf{X}=\left[\mathbf{i}, \mathbf{x}^{1}, \mathbf{x}^{2}\right], \mathbf{P}=\mathbf{Z}\left(\mathbf{Z}^{\prime} \mathbf{Z}\right)^{-1} \mathbf{Z}^{\prime}, \mathbf{i}$ is a column vector of ones and $\mathbf{Z}$ is a matrix of predetermined variables and instruments, $\kappa=\left(\lambda-\frac{1-\lambda}{n}\right) /\left(1-\frac{1-\lambda}{n}\right)$ where $\lambda$ is the minimum eigenvalue of $\mathbf{A}=\left(\overline{\mathbf{X}}^{\prime} \overline{\mathbf{X}}\right)^{-1}\left(\overline{\mathbf{X}}^{\prime} \mathbf{P} \overline{\mathbf{X}}-\sum_{i} \mathbf{P}_{i i} \mathbf{X}_{i}^{\prime} \mathbf{X}_{i}\right)$ and $\overline{\mathbf{X}}=[\mathbf{y}, \mathbf{X}]$. The authors show that, in absence of inconsistency-causing heteroscedasticity, the modified limited-information maximum likelihood is as efficient as that of Fuller (1977). When heteroscedasticity takes inconsistency-causing form, the limited-information maximum likelihood of Fuller (1977) is substantially biased, while the modified estimator results in higher precision in presence of both heteroskedasticity and many instruments.

In the next section I use both of these approaches to estimate import demand and export supply elasticities. ${ }^{5}$

\section{Data and Results}

\footnotetext{
${ }^{4}$ Following Feenstra (1994), Soderbery $(2010,2015)$ applies a two-stage estimation procedure, where in the first stage estimated residuals are used to construct a diagonal heteroscedastic covariance matrix. In the second stage the observations are weighted by the reciprocals of the diagonal elements and the limitedinformation maximum likelihood of Fuller (1977) is repeated to obtain efficient parameter estimates.

${ }^{5}$ Soderbery $(2010,2015)$ applies a two-step estimation by correcting for heteroscedasticity after the initial estimation of parameters. If, however, the first step estimation of coefficients is inconsistent, the second-step efficiency correction is of secondary importance. Accordingly, I only apply one-step estimation.
} 


\subsection{Data}

In the empirical analysis I rely on the BACI (Base pour l'Analyse du Commerce International) database that is produced by CEPII (Gaulier et al. 2008) and is a finely tuned version of the United Nations COMTRADE database. In the construction of the database a novel methodology has been applied to overcome such shortcomings of COMTRADE as missing volume information and inconsistency in units of measurement across countries and categories. The database provides bilateral export and import data for a wide range of countries at the six-digit level under the harmonized classification system (HS) from 1998 to 2013. The main trade categories are "Manufactures", "Food", "Agricultural Raw Materials", "Ores and Metals" and "Fuels". Since my interest is in comparative results of the estimators, I have chosen to use all of the categories. Finally, for the purpose of estimation, eleven eurozone countries, with average 4170 HS6 categories per country, are selected. ${ }^{6}$

\subsection{Results}

Figure 1 presents scatterplot of estimated coefficients by both methods. In the case of estimated parameters, the correlation coefficient between $\hat{\theta}_{1}^{f}$ estimated by Fuller (1977) and $\hat{\theta}_{1}^{h}$ estimated by Hausman et al (2012) is 0.64 . The correlation coefficient between $\hat{\theta}_{2}^{f}$ and $\hat{\theta}_{2}^{h}$ is similar in magnitude and stands at around 0.67. Scaterplots in Figure 2 show no correlation between implied import demand or export supply elasticities estimated by the two methods. This finding is further confirmed in Table 1 which summarizes results from bivariate regressions. The results suggest some positive relation between the implied elasticities with explained sums of squares of 0.18 and 0.03 for $\hat{\sigma}$ and $\hat{\varpi}$ respectively. A simple test of consistency is provided in row "Test" where the null hypothesis of consistently estimated parameters by Fuller (1977) is rejected. ${ }^{7}$ Thus, the findings highlight presence of substantial inconsistency caused by heteroscedasticity.

\footnotetext{
${ }^{6}$ These countries are Austria, Belgium-Luxembourg, France, Germany, Italy, Netherlands, Finland, Greece, Ireland, Portugal and Spain.

${ }^{7}$ Under the null hypothesis both estimators are consistent, while under the alternative hypothesis estimates achieved by Hausman et al (2012) are consistent while those by Fuller (1977) are not. The test is easily conducted by testing the joint significance that the intercept is zero and the slope is one.
} 
Tables 2 and 3 provide summary statistics for import and export elasticities at the six digit level for each country involved. Table 2 lists the number of elasticities satisfying theoretical conditions, $\hat{\eta}_{1}>0, \hat{\sigma}>1$ and $0<\hat{\varpi}(\hat{\sigma}-1) /(1+\hat{\sigma} \hat{\varpi})<1 .^{8}$ For instance, in the case of Germany there are 4457 categories. Of these categories only 1865 satisfactory elasticities have been obtained by the methodology of Hausman et al (2012) and 1728 by the methodology of Fuller (1977). ${ }^{9}$ The results suggest that application of Hausman et al (2012) obtains higher number of satisfactory elasticities than application of Fuller (1997).

Table 3 provides the median and interquartile range for import demand and export supply elasticities that satisfy the theoretical conditions. Panel A presents estimation results a la Hausman et al (2012). The cross-sectional average of the median elasticity of substitution stands at 1.81, while the cross-sectional average of the interquartile range is 1.33. ${ }^{10}$ Across the range of countries involved, median elasticities are very similar with cross-sectional standard deviation of median elasticities standing at 0.14 . In relation to inverse export supply elasticities, the cross-sectional average is 0.58 , while the corresponding average of the interquartile range is 1.41. As in the case of substitution elasticities, median export supply elasticities are quite similar across the range of countries involved. The cross-sectional standard deviation of the median inverse export supply elasticities is 0.06 .

Panel B of Table 3 presents estimation results a la Fuller (1977). While on aggregate the results are not substantially different from those of Panel A, the interquartile range is smaller in Panel A. In the case of substitution elasticities, out of eleven countries involved only Germany, Greece and Ireland have higher interquartile range, while in the case of inverse supply elasticities only Finland, Greece and Ireland have higher interquartile range.

\footnotetext{
${ }^{8}$ It should be mentioned that the third condition is violated quite often in my data, resulting in smaller number of estimated elasticities.

${ }^{9}$ Estimated elasticities do not necessarily belong to the same set.

${ }^{10}$ Gaulier and Mèjean (2006) estimate equation (1) with two-stage least squares. Though not comparable directly, it is interesting to note that the cross-country median elasticity of substitution obtained is 6 .
} 


\section{Limiting Cases}

Evidence presented in Table 2 suggests that in the vast majority of cases the estimated parameters violate the theoretical restrictions. This section revisits the system of demand and supply equations (1) and (2) as well as equation (4) to study the limiting behavior of the equations when the structural parameters approach their theoretical limits. It is instructive to re-write the solution of the demand/supply system in terms of shares and prices

$$
\begin{aligned}
& \Delta \ln \tilde{s}_{i, t}=\frac{\varpi+1}{\sigma \varpi+1} \Delta \ln \tilde{\varepsilon}_{i, t}-\frac{\sigma-1}{\sigma \varpi+1} \Delta \ln \tilde{u}_{i, t} \\
& \Delta \ln \tilde{p}_{i, t}=\frac{\varpi}{\sigma \varpi+1} \Delta \ln \tilde{\varepsilon}_{i, t}+\frac{1}{\sigma \varpi+1} \Delta \ln \tilde{u}_{i, t}
\end{aligned}
$$

The estimating equation has the following form

$$
\left[\Delta \ln \tilde{v}_{i, t}\right]^{2}=\frac{\varpi}{(\sigma-1)(\varpi+1)}\left[\Delta \ln \tilde{s}_{i, t}\right]^{2}-\frac{(2 \varpi-\sigma \varpi+1)}{(\sigma-1)(\varpi+1)}\left[\Delta \ln \tilde{s}_{i, t} \Delta \ln \tilde{v}_{i, t}\right]+v_{i, t}
$$

In the first case, the elasticity of substitution is allowed to approach in limit to one while the inverse supply elasticity of exports is finite, $\sigma \rightarrow 1$ and $0<\varpi<\infty$. Under these assumptions the equilibrium expenditure share is determined by the random preference shock, $\Delta \ln \tilde{s}_{i, t}=\Delta \ln \tilde{\varepsilon}_{i, t}$, while the estimating equation (4) is not defined.

When the inverse supply elasticity of exports is finite, $0<\varpi<\infty$, and $\sigma \rightarrow \infty$ then $\lim _{\sigma \rightarrow \infty} \rho=1$. Equilibrium shares and unit values are

$$
\Delta \ln \tilde{s}_{i, t}=-\frac{1}{\varpi} \Delta \ln \tilde{u}_{i, t} \text { and } \Delta \ln \tilde{v}_{i, t}=\Delta \ln \tilde{e}_{i, t}
$$

while the estimating equation is given by

$$
\left[\Delta \ln \tilde{v}_{i, t}\right]^{2}=\left[\Delta \ln \tilde{e}_{i, t}\right]^{2}+0\left[\Delta \ln \tilde{s}_{i, t}\right]^{2}+\frac{\varpi}{\varpi+1}\left[\Delta \ln \tilde{s}_{i, t} \Delta \ln \tilde{v}_{i, t}\right]+v_{i, t}
$$

The implication of large substitution elasticity is easier to see when measurement errors 
are absent. In this case both sides of the estimating equation collapse to zero causing un-identifiability of parameters. Measurement errors do not mitigate the problem, and the estimated parameters are still expected to be imprecise.

Finally, letting $\varpi \rightarrow \infty$ and $1<\sigma<\infty$, the structural equations and the estimating equation become

$$
\begin{aligned}
\Delta \ln \tilde{s}_{i, t} & =\frac{1}{\sigma} \Delta \ln \tilde{\varepsilon}_{i, t} \text { and } \Delta \ln \tilde{v}_{i, t}=\frac{1}{\sigma} \Delta \ln \tilde{\varepsilon}_{i, t}+\Delta \ln \tilde{e}_{i, t} \\
{\left[\Delta \ln \tilde{v}_{i, t}\right]^{2} } & =\left[\Delta \ln \tilde{e}_{i, t}\right]^{2}+\frac{1}{\sigma-1}\left[\Delta \ln \tilde{s}_{i, t}\right]^{2}-\frac{2-\sigma}{\sigma-1}\left[\Delta \ln \tilde{s}_{i, t} \Delta \ln \tilde{v}_{i, t}\right]+v_{i, t}
\end{aligned}
$$

The absence of measurement errors causes perfect collinearity between the variables of the estimating equation. Thus the measurement error, by breaking the perfect collinearity, only adds extra noise to the variables. Consequently, the parameters of the estimating equation are imprecisely identified. When $\sigma \rightarrow \infty$ as well, the problem of estimating the parameters in exacerbated further.

While these results are derived for cases of limiting structural parameters, similar outcomes can be expected in finite samples when structural parameters are either relatively large or small. To show this, I generate artificial data satisfying demand and supply equations (11) and (12). Following Soderbery (2010), I draw heteroscedastic variances for $\Delta \ln \tilde{\varepsilon}_{i, t}$ and $\Delta \ln \tilde{u}_{i, t}$ from a uniform distribution as follows

$$
\begin{aligned}
& \Delta \ln \tilde{\varepsilon}_{i, t} \sim N\left[0, \sigma_{\Delta \ln \tilde{\varepsilon}_{i}}^{2}\right], \text { where } \sigma_{\Delta \ln \tilde{\varepsilon}_{i}}^{2} \in(0,9) \\
& \Delta \ln \tilde{u}_{i, t} \sim N\left[0, \sigma_{\Delta \ln \tilde{u}_{i}}^{2}\right], \text { where } \sigma_{\Delta \ln \tilde{u}_{i}}^{2} \in(0,9)
\end{aligned}
$$

For the elasticities I have chosen $\sigma=[1.01 ; 2 ; 3 ; 20]$ and $\varpi=[0.01 ; 0.5 ; 1 ; 20]$. The number of varieties per importer is set equal to 55 , while the number of observations per variety is set equal to $40 .{ }^{11}$ The number of Monte Carlo simulations is set equal to 100 . Since the chosen form of heteroscedasticity does not cause consistency problems, the parameters are estimated by the limited-information maximum likelihood of Fuller (1977).

\footnotetext{
${ }^{11}$ Observe that the heteroscedasticity is not of damaging type, and the simulation is conducted with a balanced panel.
} 
The results of the simulation are summarized in columns " $\mathrm{c}$ " of Tables 4 and 5 for sigma and omega respectively. The first line presents the median bias calculated as $(\hat{\sigma}-\sigma) / \sigma$ in percentage points, while the second line presents the 9 th percentile range of the bias. Finally the third line indicates the number of parameter estimates that satisfy the theoretical restrictions. ${ }^{12}$ For instance, $\sigma=2$ and $\varpi=0.01$ pair has a corresponding median bias of 0.09 percent, while the 9 th percentile range of the bias is 2.36. For this pair the number of theoretically satisfied restrictions is $76 .{ }^{13}$ The tables reconfirm complications generated by the limiting behavior of the parameters. For a given elasticity of substitution $\sigma$, high inverse supply elasticity raises both the median bias, the percentile range and the number of violated theoretical restrictions on parameters. Similar patterns hold for given $\varpi$ and large $\sigma$ pairs.

\section{3D-Panel}

The previous section exposed some potential problems caused by the limiting behavior of the parameters. The inaccuracy of the estimates in finite samples can be shown to be inversely related to sample size. Previous studies (Feenstra 1994; Broda and Weinsten 2006; Soderbery 2010, 2015) have relied on two-dimensional panel for a given importer. In this baseline panel the variability occurs across exporters/varieties and time. Since adding more data can help mitigate the problem of imprecisions, I have added the third dimension to the panel by stacking importers and applying the same estimation technique with a common cross-sectional constant. With the same data generating process discussed above ten additional importers have been created. The results of the simulation of this three-dimensional panel are summarized in column " $\mathrm{p}$ " of Tables 4 and 5 for $\sigma$ and $\omega$ respectively. The tables highlight substantial improvements in both median bias, 9th percentile range and the number of theoretical restrictions.

Moving from simulated data to trade data, Table 6 lists the number of elasticities

\footnotetext{
${ }^{12}$ Both the median and the 9 th percentile range are computed for parameters satisfying the theoretical restrictions.

${ }^{13}$ That means that in 24 cases either $\hat{\eta}_{1}<0$ or restrictions imposed on $\rho, \sigma$ or $\omega$ fail to hold.
} 
satisfying the theoretical conditions, $\hat{\eta}_{1}>0, \hat{\sigma}>1$ and $0<\hat{\varpi}(\hat{\sigma}-1) /(1+\hat{\sigma} \hat{\varpi})<$ $1{ }^{14}$ For instance, in the case of Germany there are 2488 HS6 categories out of 3225 HS6 categories for which $\hat{\eta}_{1}>0$. Of these categories only 1374 satisfactory elasticities have been obtained by the methodology of Hausman et al (2012) applied to the baseline panel. As shown in the bottom line of Table 6, three-dimensional panel estimates result in a smaller number of satisfactory elasticities. ${ }^{15}$

Finally, columns 2 and 4 of Table 7 provide summary statistics for 3225 HS6 elasticities estimated by the methodology of Hausman et al (2012) applied to the baseline panel, averaged across 11 eurozone countries. Columns 3 and 5 describe summary statistics of elasticities for the same group of HS6 categories estimated by the methodology of Hausman et al (2012) applied to the three-dimensional panel. All of the statistics are smaller for the latter estimates relative to the baseline panel. For instance, the median elasticity of substitution in the extended panel is 1.21 with an interquartile range of 0.38 . The corresponding median and interquartile range of averaged elasticities in the baseline panel are 1.94 and 0.99 respectively. In relation to the inverse supply elasticities, the median and interquartile range are 0.33 and 0.77 in the extended panel, while in the baseline panel the median and interquartile range are 1.23 and 1.74 .

\section{Conclusions}

Following the seminal contribution of Feentra(1994), I estimate import demand and export supply elasticities for a range of eurozone countries. The results highlight substantial inconsistencies in the parameters estimated by the methodology of Fuller (1977) relative to those estimated by the methodology of Hausman et al (2012). The nature of structural equations reveals complications generated by the limiting behavior of the parameters that can be replicated in finite samples. The results of the simulations highlight substantial improvements in parameter estimates in the extended panel relative to the

\footnotetext{
${ }^{14}$ The sample comprises common HS6 categories, as opposed to all categories in Table 6.

${ }^{15}$ This is not surprising for two reasons. Firstly, elasticities could very by country. Second, the CES structure of preferences might not be appropriate in general.
} 
baseline panel, suggesting that the problem of limiting behaviour can be overcome in larger datasets/panels. 


\section{References}

Broda, Christian and David Weinstein (2006), "Globalization and the Gains from Variety," Quarterly Journal of Economics 121, 541-585.

Davidson, Russel and James MacKinnon (1993), Estimation and Inference in Econometrcis, Oxford University Press.

Feenstra, Robert (1994), “New Product Varieties and the Measurement of International Prices," American Economic Review 84, 157-177.

Fuller, Wayne (1977), "Some Properties of a Modification of the Limited Information Estimator ," Econometrica 45, 939-953.

Gaulier, Guillaume and Isabelle Mejean (2007), “Import Prices, Variety and the Extensive Margin of Trade," CEPII Working Paper No. 2006-17.

Gaulier, Guillaume, Soledad Zignago and Rodrigo Paillacar (2010), “BACI: International Trade Database at the Product-Level. The 1994-2007 Version," CEPII Working Paper 23.

Hausman, Jerry, Whitney Newey, Tiemen Woutersen, John Chao and Norman Swanson (2012), "Instrumental Variable Estimation with Heteroskedasticity and Many Instruments," Quantitative Economics 3, 211-255.

Soderbery, Anson (2010), “Investigating the Asymptotic Properties of Elasticity of Substitution Estimates," Economics Letters 190, 57-62.

Soderbery, Anson (2015), “Estimating Import Supply and Demand Elasticities: Analysis and Implications," Journal of International Economics 96, 1-17. 
Figure 1: Estimated Coefficients
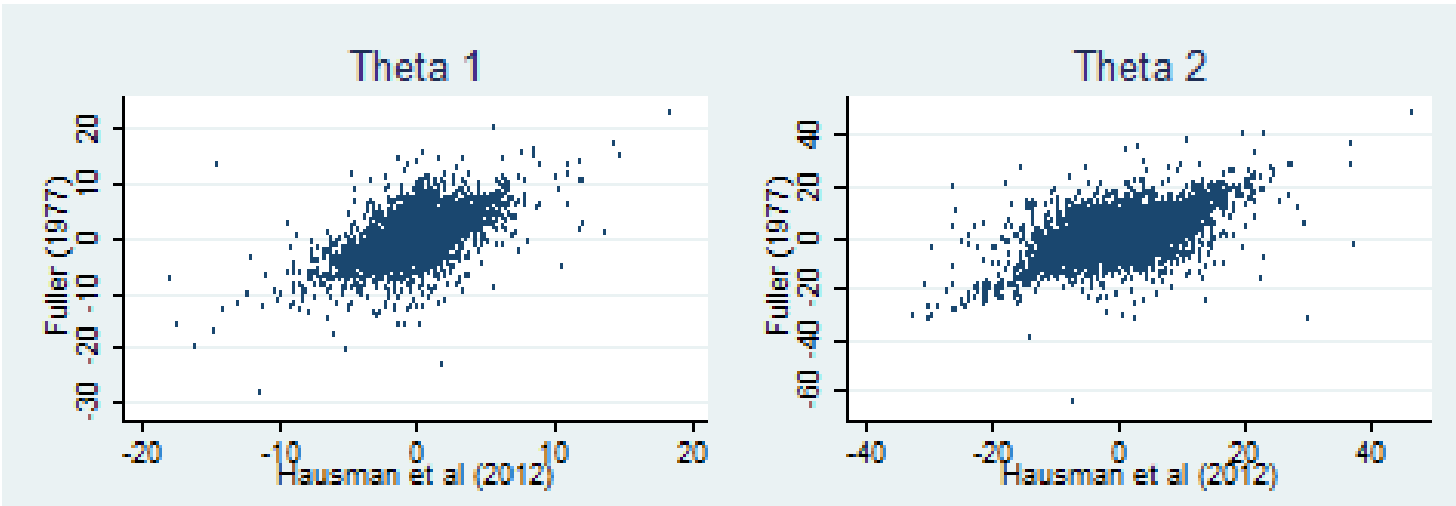

Note: The graph presents scatterplots of estimated coefficients by the methods of Fuller (1977) and Hausman et al (2012). 
Figure 2: Implied Elasticities
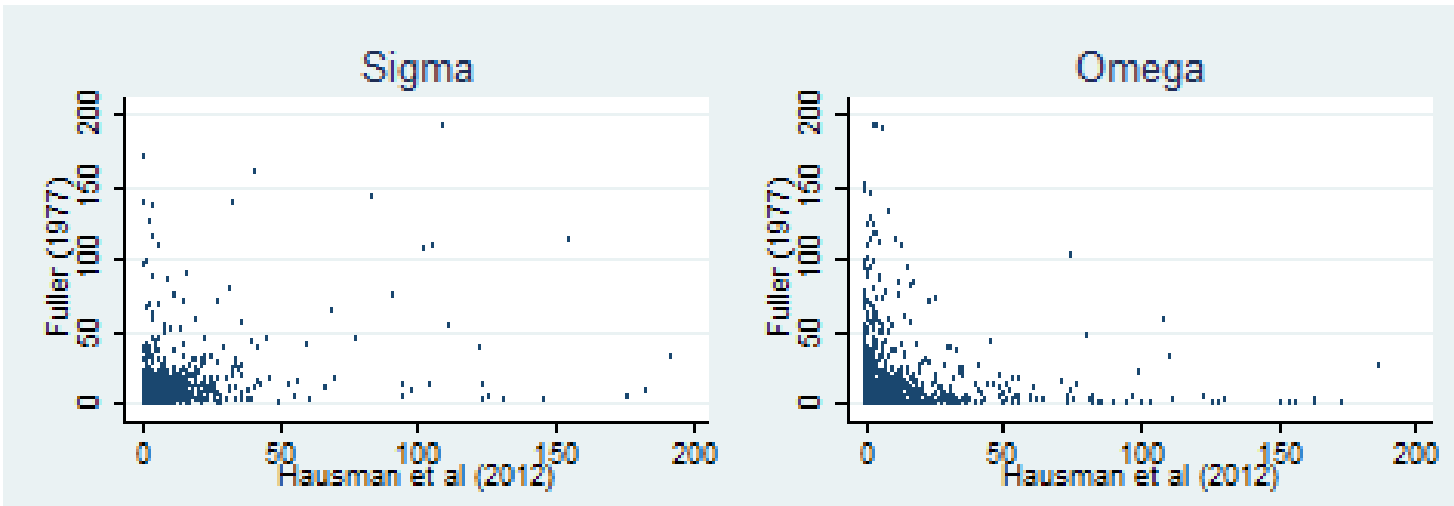

Note: The graph presents scatterplots of implied import demand and export supply elasticities. Derived from coefficients estimated by the methods of Fuller (1977) and Hausman et al (2012). 
Table 1: Summary Correlations

\begin{tabular}{lllll}
\hline \hline & & & & \\
& $\hat{\theta}_{1}^{f}$ & $\hat{\theta}_{2}^{f}$ & $\hat{\sigma}^{f}$ & $\hat{\omega}^{f}$ \\
& & & & \\
$\hat{\theta}_{1}^{h}$ & 0.86 & & & \\
& $(0.00)^{* * *}$ & & & \\
$\hat{\theta}_{2}^{h}$ & & 0.73 & & \\
$\hat{\sigma}^{h}$ & & $(0.00)^{* * *}$ & & \\
& & & 0.43 & \\
$\hat{\omega}^{h}$ & & & $(0.01)^{* * *}$ & \\
& & & & 0.18 \\
Const. & 0.03 & 0.05 & 1.72 & $(0.01)^{* * *}$ \\
& $(0.01)^{* * *}$ & $(0.01)^{* * *}$ & $(0.06)^{* * *}$ & $(0.08)^{* * *}$ \\
Test & $406^{* * *}$ & $2564^{* * *}$ & $2333^{* * *}$ & $3311^{* * *}$ \\
Obs. & 45,803 & 45,803 & 12,166 & 12,166 \\
$R^{2}$ & 0.41 & 0.44 & 0.18 & 0.03 \\
& & & & \\
\hline \hline
\end{tabular}

Notes: "Test" describes the Wald statistic for the joint significance that the intercept is zero and the slope is one. Under the null hypothesis both estimators are consistent, while under the alternative hypothesis estimates achieved by Hausman et al (2012) are consistent while those by Fuller (1977) are not. Estimated with OLS. Asterisks $* * * * *, *$ indicate significance at $1 \%, 5 \%$ and $10 \%$ levels 
Table 2: Theoretical Restrictions

\begin{tabular}{lccccc}
\hline \hline & Obs. & $\hat{\theta}_{1}^{h}>0$ & $\begin{array}{c}\hat{\sigma}^{h}>1 \\
\hat{\omega}^{h}>0\end{array}$ & $\hat{\theta}_{1}^{f}>0$ & $\begin{array}{l}\hat{\sigma}^{f}>1 \\
\hat{\omega}^{f}>0\end{array}$ \\
\hline Austria & 4237 & 55.7 & 28.9 & 53.8 & 27.6 \\
Bel-Lux & 4369 & 65.7 & 38.0 & 61.3 & 33.6 \\
France & 4461 & 65.6 & 32.0 & 61.9 & 30.0 \\
Germany & 4457 & 73.5 & 41.8 & 68.7 & 38.8 \\
Italy & 4378 & 72.3 & 46.0 & 66.4 & 38.8 \\
Netherlands & 4267 & 66.2 & 38.8 & 60.7 & 34.3 \\
Finland & 3651 & 61.1 & 33.2 & 57.7 & 30.9 \\
Greece & 3728 & 62.0 & 38.9 & 60.0 & 36.2 \\
Ireland & 3908 & 57.0 & 30.4 & 56.1 & 29.5 \\
Portugal & 4007 & 62.9 & 43.0 & 59.3 & 39.4 \\
Spain & 4340 & 69.9 & 43.5 & 65.6 & 40.1 \\
\hline \hline
\end{tabular}

Notes: The table lists the number of elasticities satisfying theoretical conditions, $\hat{\eta}_{1}>0, \hat{\sigma}>1$ and $0<\hat{\varpi}(\hat{\sigma}-1) /(1+\hat{\sigma} \hat{\varpi})<1$. 
Table 3: Summary Statistics

\begin{tabular}{|c|c|c|c|c|c|}
\hline Panel A & Obs. & $\begin{array}{c}\hat{\sigma}^{h} \\
\text { Median }\end{array}$ & $\begin{array}{c}\hat{\sigma}^{h} \\
\mathrm{IQR}\end{array}$ & $\begin{array}{c}\hat{\omega}^{h} \\
\text { Median }\end{array}$ & $\begin{array}{c}\hat{\omega}^{h} \\
\mathrm{IQR}\end{array}$ \\
\hline Austria & 1223 & 1.65 & 1.14 & 0.62 & 1.50 \\
\hline Bel-Lux & 1659 & 1.74 & 1.21 & 0.48 & 1.33 \\
\hline France & 1428 & 1.67 & 1.08 & 0.56 & 1.48 \\
\hline Germany & 1865 & 1.80 & 1.31 & 0.55 & 1.41 \\
\hline Italy & 2014 & 1.78 & 1.16 & 0.56 & 1.35 \\
\hline Netherlands & 1656 & 1.80 & 1.21 & 0.52 & 1.22 \\
\hline Finland & 1213 & 1.73 & 1.27 & 0.52 & 1.49 \\
\hline Greece & 1450 & 1.82 & 1.41 & 0.72 & 1.58 \\
\hline Ireland & 1189 & 2.04 & 1.90 & 0.59 & 1.53 \\
\hline Portugal & 1722 & 2.10 & 1.81 & 0.61 & 1.21 \\
\hline Spain & 1886 & 1.78 & 1.12 & 0.59 & 1.38 \\
\hline Panel B & Obs. & $\begin{array}{c}\hat{\sigma}^{f} \\
\text { Median }\end{array}$ & $\begin{array}{c}\hat{\sigma}^{f} \\
\mathrm{IQR}\end{array}$ & $\begin{array}{c}\hat{\omega}^{f} \\
\text { Median }\end{array}$ & $\begin{array}{c}\hat{\omega}^{f} \\
\mathrm{IQR}\end{array}$ \\
\hline Austria & 1171 & 1.75 & 1.49 & 0.72 & 1.81 \\
\hline Bel-Lux & 1470 & 1.74 & 1.32 & 0.51 & 1.35 \\
\hline France & 1340 & 1.68 & 1.37 & 0.69 & 1.66 \\
\hline Germany & 1728 & 1.72 & 1.24 & 0.56 & 1.52 \\
\hline Italy & 1697 & 1.74 & 1.27 & 0.60 & 1.42 \\
\hline Netherlands & 1462 & 1.75 & 1.29 & 0.52 & 1.44 \\
\hline Finland & 1127 & 1.76 & 1.29 & 0.49 & 1.42 \\
\hline Greece & 1349 & 1.77 & 1.29 & 0.67 & 1.54 \\
\hline Ireland & 1153 & 1.93 & 1.84 & 0.56 & 1.31 \\
\hline Portugal & 1579 & 2.04 & 1.82 & 0.59 & 1.34 \\
\hline Spain & 1742 & 1.77 & 1.14 & 0.56 & 1.43 \\
\hline
\end{tabular}

Notes: Panel A describes the estimation results based on Hausman et al (2012), while Panel B by describes the estimation results based on Fuller (1977). 
Table 4: Simulation Results for Sigma

\begin{tabular}{|c|c|c|c|c|c|c|c|c|}
\hline & \multicolumn{2}{|c|}{$\sigma=1.01$} & \multicolumn{2}{|c|}{$\sigma=2$} & \multicolumn{2}{|c|}{$\sigma=3$} & \multicolumn{2}{|c|}{$\sigma=20$} \\
\hline & c & p & c & $\mathbf{p}$ & c & p & c & $\mathrm{p}$ \\
\hline$\omega=c$ & $\begin{array}{l}1.27 \\
(4.06) \\
{[60]}\end{array}$ & $\begin{array}{l}0.07 \\
(0.62) \\
{[99]}\end{array}$ & $\begin{array}{l}0.09 \\
(2.36) \\
{[76]}\end{array}$ & $\begin{array}{l}0.03 \\
(0.70) \\
{[96]}\end{array}$ & $\begin{array}{l}-0.05 \\
(2.50) \\
{[70]}\end{array}$ & $\begin{array}{l}0.02 \\
(0.65) \\
{[95]}\end{array}$ & $\begin{array}{l}-0.16 \\
(2.01) \\
{[10]}\end{array}$ & $\begin{array}{l}-0.03 \\
(1.12) \\
{[35]}\end{array}$ \\
\hline$\omega=0.5$ & $\begin{array}{l}2.69 \\
(9.48) \\
{[69]}\end{array}$ & $\begin{array}{l}0.12 \\
(0.95) \\
{[97]}\end{array}$ & $\begin{array}{l}0.42 \\
(6.42) \\
{[100]}\end{array}$ & $\begin{array}{l}0.20 \\
(1.64) \\
{[100]}\end{array}$ & $\begin{array}{l}0.43 \\
(6.87) \\
{[100]}\end{array}$ & $\begin{array}{l}0.12 \\
(2.28) \\
{[100]}\end{array}$ & $\begin{array}{l}-1.50 \\
(36.8) \\
{[57]}\end{array}$ & $\begin{array}{l}-0.67 \\
(11.8) \\
{[59]}\end{array}$ \\
\hline$\omega=1$ & $\begin{array}{l}4.80 \\
(18.1) \\
{[59]}\end{array}$ & $\begin{array}{l}0.22 \\
(1.12) \\
{[95]}\end{array}$ & $\begin{array}{l}0.49 \\
(10.1) \\
{[100]}\end{array}$ & $\begin{array}{l}-0.03 \\
(2.47) \\
{[100]}\end{array}$ & $\begin{array}{l}-0.08 \\
(12.8) \\
{[100]}\end{array}$ & $\begin{array}{l}0.18 \\
(3.08) \\
{[100]}\end{array}$ & $\begin{array}{l}-0.76 \\
(72.2) \\
{[44]}\end{array}$ & $\begin{array}{l}-0.80 \\
(26.0) \\
{[42]}\end{array}$ \\
\hline$\omega=20$ & $\begin{array}{l}224 \\
(254) \\
{[6]}\end{array}$ & $\begin{array}{l}327 \\
(2307) \\
{[18]}\end{array}$ & $\begin{array}{l}78.2 \\
(3350) \\
{[18]}\end{array}$ & $\begin{array}{l}-16.5 \\
(430) \\
{[41]}\end{array}$ & $\begin{array}{l}-34.6 \\
(357) \\
{[31]}\end{array}$ & $\begin{array}{l}-52.4 \\
(344) \\
{[53]}\end{array}$ & $\begin{array}{l}-92.7 \\
(17.0) \\
{[35]}\end{array}$ & $\begin{array}{l}-86.4 \\
(49.0) \\
{[43]}\end{array}$ \\
\hline
\end{tabular}

Notes: The number of varieties per importer is set equal to 55 , while the number of observations per variety is set equal to 40 . The number of Monte Carlo experiments is set equal to 100 . " $\mathrm{c}$ " stands for country-level simulation while " $\mathrm{p}$ " stand for panel simulations. Estimated by the methodology of Fuller (1977). 
Table 5: Simulation Results for Omega

\begin{tabular}{|c|c|c|c|c|c|c|c|c|}
\hline & \multicolumn{2}{|c|}{$\sigma=1.01$} & \multicolumn{2}{|c|}{$\sigma=2$} & \multicolumn{2}{|c|}{$\sigma=3$} & \multicolumn{2}{|c|}{$\sigma=20$} \\
\hline & c & p & C & p & C & $\mathbf{p}$ & c & $\mathbf{p}$ \\
\hline$\omega=0.01$ & $\begin{array}{l}7.77 \\
(329) \\
{[60]}\end{array}$ & $\begin{array}{l}-7.71 \\
(112) \\
{[99]}\end{array}$ & $\begin{array}{l}21.7 \\
(436) \\
{[76]}\end{array}$ & $\begin{array}{l}0.12 \\
(155) \\
{[96]}\end{array}$ & $\begin{array}{l}46.2 \\
(354) \\
{[70]}\end{array}$ & $\begin{array}{l}3.30 \\
(210) \\
{[95]}\end{array}$ & $\begin{array}{l}106 \\
(622) \\
{[10]}\end{array}$ & $\begin{array}{l}401 \\
(2970) \\
{[35]}\end{array}$ \\
\hline$\omega=0.5$ & $\begin{array}{l}-0.62 \\
(16.0) \\
{[69]}\end{array}$ & $\begin{array}{l}-0.51 \\
(4.93) \\
{[97]}\end{array}$ & $\begin{array}{l}0.18 \\
(23.8) \\
{[100]}\end{array}$ & $\begin{array}{l}-0.04 \\
(6.96) \\
{[100]}\end{array}$ & $\begin{array}{l}-0.78 \\
(28.4) \\
{[100]}\end{array}$ & $\begin{array}{l}-0.42 \\
(11.6) \\
{[100]}\end{array}$ & $\begin{array}{l}-31.7 \\
(297) \\
{[57]}\end{array}$ & $\begin{array}{l}4.68 \\
(4690) \\
{[59]}\end{array}$ \\
\hline$\omega=1$ & $\begin{array}{l}-0.52 \\
(15.4) \\
{[59]}\end{array}$ & $\begin{array}{l}-0.05 \\
(3.63) \\
{[95]}\end{array}$ & $\begin{array}{l}-1.19 \\
(19.0) \\
{[100]}\end{array}$ & $\begin{array}{l}-0.01 \\
(6.26) \\
{[100]}\end{array}$ & $\begin{array}{l}-1.46 \\
(33.7) \\
{[100]}\end{array}$ & $\begin{array}{l}0.12 \\
(12.9) \\
{[100]}\end{array}$ & $\begin{array}{l}-30.9 \\
(360) \\
{[44]}\end{array}$ & $\begin{array}{l}19.8 \\
(8066) \\
{[42]}\end{array}$ \\
\hline$\omega=20$ & $\begin{array}{l}8.36 \\
(47.2) \\
{[6]}\end{array}$ & $\begin{array}{l}0.78 \\
(34.3) \\
{[18]}\end{array}$ & $\begin{array}{l}-6.05 \\
(140) \\
{[18]}\end{array}$ & $\begin{array}{l}0.93 \\
(50.2) \\
{[41]}\end{array}$ & $\begin{array}{l}3.80 \\
(2468) \\
{[31]}\end{array}$ & $\begin{array}{l}-0.70 \\
(59.9) \\
{[53]}\end{array}$ & $\begin{array}{l}-91.3 \\
(49.2) \\
{[35]}\end{array}$ & $\begin{array}{l}-82.7 \\
(94.7) \\
{[43]}\end{array}$ \\
\hline
\end{tabular}

Notes: The number of varieties per importer is set equal to 55 , while the number of observations per variety is set equal to 40 . The number of Monte Carlo experiments is set equal to 100 . " $c$ " stands for country-level simulation while " $\mathrm{p}$ " stand for panel simulations. Estimated by the methodology of Fuller (1977). 
Table 6: Panel Results

\begin{tabular}{lcccc}
\hline \hline & $\hat{\theta}_{1}^{h}>0$ & $\begin{array}{c}\hat{\sigma}^{h}>1 \\
\hat{\omega}^{h}>0\end{array}$ & $\begin{array}{c}\hat{\theta}_{1}^{h}>0 \\
\text { in \% }\end{array}$ & $\begin{array}{c}\hat{\sigma}^{h}>1 \\
\hat{\omega}^{h}>0 \\
\text { in \% }\end{array}$ \\
\hline Austria & 1868 & 947 & 57.9 & 29.4 \\
Bel-Lux & 2248 & 1278 & 69.7 & 39.6 \\
France & 2199 & 1020 & 68.2 & 31.6 \\
Germany & 2488 & 1374 & 77.1 & 42.6 \\
Italy & 2427 & 1503 & 75.3 & 46.6 \\
Netherlands & 2244 & 1257 & 69.6 & 39.0 \\
Finland & 2030 & 1076 & 62.9 & 33.4 \\
Greece & 2057 & 1261 & 63.8 & 39.1 \\
Ireland & 1881 & 953 & 58.3 & 29.6 \\
Portugal & 2113 & 1400 & 65.5 & 43.4 \\
Spain & 2359 & 1423 & 73.1 & 44.1 \\
Panel & 2252 & 1015 & 69.8 & 31.5 \\
& & & & \\
\hline \hline
\end{tabular}

Notes: Estimated by the methodology of Hausman et al (2012). Overall there are 3225 HS6 categories per country. 
Table 7: Panel vs Cross-sectional Average

\begin{tabular}{lcccc}
\hline \hline & & & & \\
& $\hat{\sigma}_{c a}^{h}$ & $\hat{\sigma}_{p}^{h}$ & $\hat{\omega}_{c a}^{h}$ & $\hat{\omega}_{p}^{h}$ \\
\hline $\mathrm{P}(1)$ & 1.25 & 1.04 & 0.17 & 0.01 \\
$\mathrm{P}(5)$ & 1.36 & 1.06 & 0.29 & 0.03 \\
$\mathrm{P}(10)$ & 1.43 & 1.08 & 0.39 & 0.04 \\
$\mathrm{P}(25)$ & 1.60 & 1.11 & 0.69 & 0.12 \\
$\mathrm{P}(50)$ & 1.94 & 1.21 & 1.23 & 0.33 \\
$\mathrm{P}(75)$ & 2.59 & 1.49 & 2.43 & 0.89 \\
$\mathrm{P}(90)$ & 3.89 & 2.02 & 5.42 & 2.96 \\
$\mathrm{P}(95)$ & 5.32 & 2.52 & 10.9 & 6.11 \\
$\mathrm{P}(99)$ & 13.0 & 5.96 & 59.0 & 39.2 \\
& & & & \\
Mean & 2.91 & 1.47 & 8.59 & 2.66 \\
Median & 1.94 & 1.21 & 1.23 & 0.33 \\
IQR & 0.99 & 0.38 & 1.74 & 0.77 \\
Skewness & 22.7 & 6.04 & 25.5 & 19.1 \\
Kurtosis & 593 & 51 & 690 & 420 \\
& & & & \\
\hline \hline
\end{tabular}

Notes: Estimated by the methodology of Hausman et al (2012). Overall there are 3225 HS6 categories per country. 